\title{
Evaluation of Anti Fertility Activities of Bark Extracts of Caesalpinia pulcherrima Linn. (Caesalpiniaceae) in Rats
}

\author{
R. SHAIK, S. K. MOHAMAD* AND N. V. RAO \\ V. L. College of Pharmacy, Raichur, Karnataka 584103, India
}

Shaik et al.: Anti-fertility activities of Caesalpinia pulcherrima Linn. in rats

\begin{abstract}
The present study was aimed to evaluate the anti-ferlility activity of Caesalpinia pulcherrima Linn. in rats. The plant Caesalpinia pulcherrima is a shrub or small tree. The plant is normally considered to be an ornamental shrub which is planted in gardens and parks for its beautiful red or yellow flowers. The phytochemical screening of the plant has shown the presence of various chemical constituents like alkaloids, flavonoids, steroids and triterpenes. The bark extracts of Caesalpinia pulcherrima have exhibited significant estrogenic activity. Both the aqueous and alcoholic extracts have produced reduction in ovarian and increase in uterine weight in a dose dependent manner. Also there is a significant increase in antiimplantation and resorption in a dose dependent manner. The activity shown can be attributed to the presence of phytochemical constituents.
\end{abstract}

Key words: Caesalpinia pulcherrima, anti-fertility activity, saponins, steroids

In the present scenario most emerging problem with the underdeveloped and developing countries is population growth. It itself leads to various other problems like lack of employment opportunities, poverty, illiteracy, low living standards and many more. Providing with birth control measures and educating with the same can avoid the population growth to some extent. Thus it can indirectly help for the growth a country in a positive manner. At present there are several methods to control fertility but these methods can end with complications which make them to use at a lesser extent ${ }^{[1]}$. So the present study was aimed to explore the natural potential of herbs as anti-fertility agent. The plant $C$. pulcherrima is a shrub or small tree ${ }^{[2]}$. The plant contains a flavonoid, myricitroside. The leaves, flowers and fruit contain tannins, gums, resin and benzoic acid. Presence of cyanidin, diglucoside is also reported from the flowers and hydrocyanic acid from the leaves. The root contains caesalpin type diterpenoids along with sitostero[ ${ }^{[3]}$. The bark of the C. pulcherrima was collected from Raichur, Karnataka, India and was authenticated and confirmed by Dr. V. Hemant Kumar, Botanist V.L. College of Pharmacy, Raichur, Karnataka. The alcoholic (AEBCP) extract of dried bark powder was obtained through soxhalation and the aqueous extract (AQEBCP) was prepared by maceration process. The obtained filtrate was concentrated on the water bath ${ }^{[4-6]}$. Albino rats

*Address for correspondence

E-mail: msmvlcp4@gmail.com

March-April 2021
(Wistar strain) of either sex weighing between 150-200 $\mathrm{g}$ and Albino mice of either sex (16-20 g) were procured from National Centre for Laboratory Animal Sciences, $\mathrm{C} / \mathrm{O}$ Sri Venkateswara Enterprises, Bengaluru for experimental purpose. All animal studies were performed in accordance to the Guidelines of committee for the purpose of control and supervision of experiments on animals (CPCSEA) (Registration Number 557/02/c/CPCSEA) and Institutional Animal Ethical Committee (IAEC) of V.L. College of Pharmacy, Raichur (Karnataka) and all the procedures were followed as per rules and regulations. The oral acute toxicity of AQEBCP and AEBCP was determined by following procedure of OECD Guidelines No.425 method of CPCSEA, from the observed $\mathrm{LD}_{50}$ doses $1 / 20^{\text {th }}, 1 / 10^{\text {th }}$ and $1 / 5^{\text {th }}$ doses were selected for the present study considered as low, medium and high doses respectively. The treatment protocol for different groups of rats is given below. Group 1-Normal control (distilled water); Group-2-Standard $\beta$-Estradiol 3-benzoate in olive oil $(0.1 \mathrm{mg} / \mathrm{kg}$ daily for $20 \mathrm{~d})$; This is an open access article distributed under the terms of the Creative
Commons Attribution-NonCommercial-ShareAlike 3.0 License, which
allows others to remix, tweak, and build upon the work non-commercially,
as long as the author is credited and the new creations are licensed under
the identical terms Indian J Pharm Sci 2021;83(2):393-397 
Group-3-AEBCP low dose $(100 \mathrm{mg} / \mathrm{kg})$ for $20 \mathrm{~d}$ p.o; Group-4-AEBCP medium dose $(200 \mathrm{mg} / \mathrm{kg})$ for $20 \mathrm{~d}$ p.o; Group-5-AEBCP high dose $(400 \mathrm{mg} / \mathrm{kg})$ for $20 \mathrm{~d}$ p.o; Group-6-AQEBCP low dose $(100 \mathrm{mg} / \mathrm{kg})$ for $20 \mathrm{~d}$ p.o; Group-7-AQEBCP medium dose $(200 \mathrm{mg} / \mathrm{kg})$ for $20 \mathrm{~d}$ p.o; Group-8-AQEBCP high dose (400 mg/kg) for $20 \mathrm{~d}$ p.o. Adult female (Wistar) rats weighing between 150-160 g were mated with adult males and vaginal smears were observed under a microscope. D 1 of pregnancy was designated as the day on which spermatozoa was observed in the vaginal smear. Pregnant rats in the group III- V were killed on d 9 of pregnancy and percent anti-implantation was determined. Rats in the groups VI-VIII were killed on d 20 of pregnancy. Percent abortion was determined by dividing the percent of resorption by the number of implantation sites. Other groups of pregnant rats were allowed to labor in which the labor time, litter size, number of dead and viable fetuses were recorded. Determination of viable fetuses was based on gross appearance of live fetuses at the time of labor ${ }^{[7]}$. Percentage of resorption index $=$ no of animals aborted $\times 100 /$ No of implantations. Percentage of animals aborted $=$ No of implants-No of litters. Group-1Normal control (distilled water); Group-2-Standard $\beta$-Estradiol 3-benzoate in olive oil $(0.1 \mathrm{mg} / \mathrm{kg}$ daily for $15 \mathrm{~d})$; Group-3-Low dose $(100 \mathrm{mg} / \mathrm{kg})$ to AEBCP for 15 d p.o; Group-4-Medium dose (200 mg/kg) to AEBCP for $15 \mathrm{~d}$ p.o; Group-5-High dose (400 mg/ $\mathrm{kg}$ ) of AEBCP for $15 \mathrm{~d}$ p.o; Group-6-Low dose $(100 \mathrm{mg} / \mathrm{kg})$ of AQEBCP for 15 d p.o; Group-7-Medium dose (200 $\mathrm{mg} / \mathrm{kg}$ ) of AQEBCP for $15 \mathrm{~d}$ p.o; Group-8-High dose $(400 \mathrm{mg} / \mathrm{kg}$ ) of AQEBCP for $15 \mathrm{~d}$ p.o. Female rats were divided into 8 groups $(n=6)$, vaginal smear from each rat were examined daily for $15 \mathrm{~d}$ and those rats exhibiting three regular cycles were considered for experiment and treated with vehicle, standard and extracts at low, medium and high doses p.o. daily once for $15 \mathrm{~d}$ in the estrus phase. The $15 \mathrm{~d}$ treatment should cover three regular estrus cycles. Vaginal smear from each animal were observed every morning between 9-10 AM. On the $16^{\text {th }} \mathrm{d}, 24 \mathrm{~h}$ after the treatment of last dose, the rats from each group will be anesthetized and sacrificed. Ovaries and uteri were dissected out, free from extra deposition and are weighed ${ }^{[8]}$. All the data is analyzed using graph Pad Prism by following one way Analysis of variance (ANOVA) and are considered significant at $\mathrm{p}<0.05$. In vehicle treated control group number of litters is noted as $(10.67 \pm 0.6667)$ standard $\beta$-Estradiol 3-benzoate treated group is noted with $(0.0 \pm 0.0)$ litters. A significant and dose dependent reduction in number of litters is recorded with AEBCP $(5.667 \pm 0.5578, \quad 4.500 \pm 1.522, \quad 0.6667 \pm 0.4216) \quad$ and $\operatorname{AQEBCP}(8.333 \pm 0.5578,7.167 \pm 0.6009,5.833 \pm 0.7923)$ treated groups at three different dose levels. AEBCP exhibited relatively better effect than AQEBCP, higher dose of AEBCP treated group is noted with $(0.0)$ number of litters. In control group $(10.67 \pm 0.6667)$ it is noted that all litters are alive. No litters are formed after treatment with standard $\beta$-Estradiol 3-benzoate $(0.0 \pm 0.0)$. Hence there is no chance for live litters. A significant reduction in number of live litters is noted with AEBCP $(3.833 \pm 0.5426,2.333 \pm 0.9189,0.0 \pm 0.0$ ) and AQEBCP $\quad(7.667 \pm 0.4216, \quad 6.167 \pm 0.4773$, $4.167 \pm 0.4773$ ) treated rats. AEBCP exhibited relatively better antifertility activity than $\mathrm{AQEBCP}$ further higher dose of AEBCP is noted with (0.0) of live litters. In normal control no dead litters are noted and the group treated with standard $\beta$-Estradiol 3-benzoate also recorded with no dead litters as this group is already noted with $(0.0 \pm 0.0)$ number of litters. A significant increase in number of dead litters is noted with AEBCP

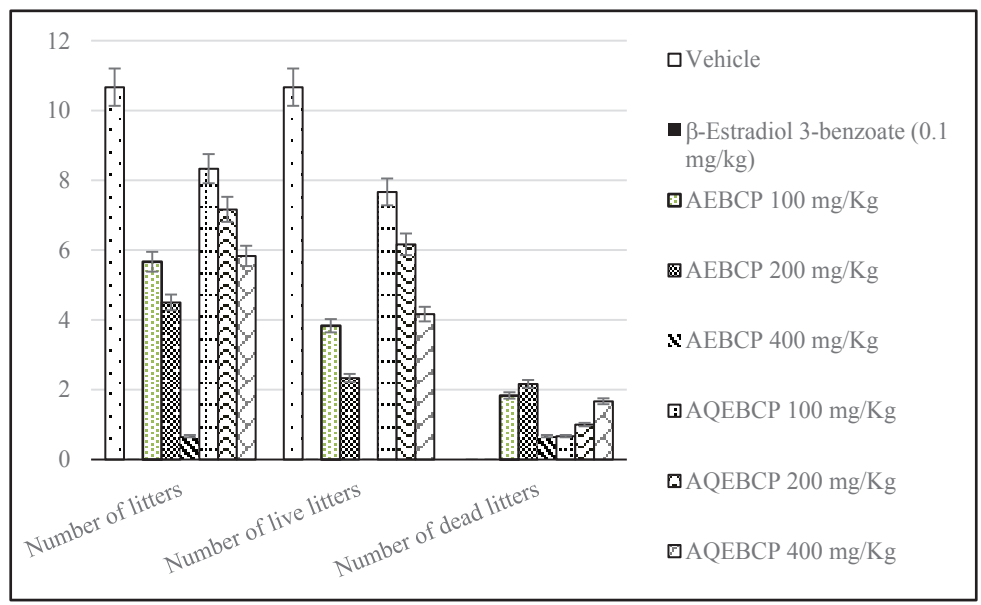

Fig. 1: Antifertility effect of $\beta$-Estradiol 3-benzoate, AEBCP and AQEBCP on number of litters, live litters and dead litters in rat model 
$(1.833 \pm 0.7491, \quad 2.167 \pm 0.3073, \quad 0.6667 \pm 0.3333)$ and AQEBCP $\quad(0.6667 \pm 0.4216, \quad 1.000 \pm 0.4216$, $1.667 \pm 0.2582)$ treated groups at three different dose levels. However AEBCP exhibited relatively better antifertility activity than AQEBCP (fig. 1). In normal control no anti-implantation is noted where in standard drug $\beta$-Estradiol 3-benzoate treated group (100\%) antiimplantation effect is noted. A dose dependent and significant anti implantation effect is noted with AEBCP (36.16\%, 37.5\%, $43.16 \%)$ and AQEBCP (19.5\%, $25.08 \%, 37.58 \%$ ) treated groups at three different dose levels as mentioned earlier. AEBCP exhibited relatively better anti-implantation effect than AQEBCP. In normal control group $(00.0 \%)$ and in standard drug $\beta$-Estradiol 3-benzoate treated group (100\%) resorption is noted. Both the AEBCP $(26.10 \%, 40 \%, 90.32 \%)$ and AQEBCP (13.76\%, $20.35 \%, 22.16 \%)$ exhibited a significant and dose dependent $\%$ resorption effect and AEBCP exhibited relatively better effect than AQEBCP (Table 1). In normal control group average uterine weight is noted as $(87.40 \pm 3.397 \mathrm{mg} / 100 \mathrm{~g})$. A significant increase in uterine weight is noted with standard drug
$\beta$-Estradiol 3-benzoate treated group (185.6 \pm 5.484 $\mathrm{mg} / 100 \mathrm{~g}$ ) when compared to vehicle treated control group. A significant and dose dependent increase in uterine weights are noted with AEBCP $(145.1 \pm 5.063$ $\mathrm{mg} / 100 \mathrm{~g}, 161.3 \pm 7.446 \mathrm{mg} / 100 \mathrm{~g}, 179.5 \pm 2.808 \mathrm{mg} / 100$ g) and AQEBCP $(92.74 \pm 1.591 \mathrm{mg} / 100 \mathrm{~g}, 113.7 \pm 3.377$ $\mathrm{mg} / 100 \mathrm{~g}, 127.8 \pm 0.981 \mathrm{mg} / 100 \mathrm{~g}$ ) treated rats at three different dose levels AEBCP exhibited relatively better anti-ovulatory effect in uterine weight than AQEBCP (Table 2). In normal control group average ovary weight is noted as $(56.92 \pm 0.6964 \mathrm{mg} / 100 \mathrm{~g})$. When compared to the normal control, standard drug $\beta$-Estradiol 3-benzoate treated group the ovary weight is significantly decreased $(43.16 \pm 0.7647 \mathrm{mg} / 100 \mathrm{~g})$. Where in the groups treated with three different doses of AEBCP $(51.70 \pm 0.8267 \mathrm{mg} / 100 \mathrm{~g}, 48.67 \pm 1.017$ $\mathrm{mg} / 100 \mathrm{~g}, 45.31 \pm 0.5816 \mathrm{mg} / 100 \mathrm{~g})$ and AQEBCP $(56.26 \pm 0.7319 \mathrm{mg} / 100 \mathrm{~g}, 54.09 \pm 1.220 \mathrm{mg} / 100 \mathrm{~g}$, $52.87 \pm 1.048 \mathrm{mg} / 100 \mathrm{~g}$ ) a significant reduction in ovary weight is recorded except with low dose of AQBCP treated group. Adose dependent effect is noted with both the extracts (fig. 2). The development of a country

TABLE 1: ANTIFERTILITY EFFECT OF B-ESTRADIOL 3-BENZOATE, AEBCP AND AQEBCP ON NUMBER, LIVE AND DEAD LITTERS IN RAT MODEL

\begin{tabular}{lcccccc}
\hline Groups & Treatment & $\begin{array}{c}\text { Number of } \\
\text { litters }\end{array}$ & $\begin{array}{c}\text { Number of live } \\
\text { litters }\end{array}$ & $\begin{array}{c}\text { Number of dead } \\
\text { litters }\end{array}$ & $\begin{array}{c}\text { \% Anti } \\
\text { implantation }\end{array}$ & \% Resorption \\
\hline I & $\begin{array}{c}\text { Vehicle (distilled water) } \\
\text { B-Estradiol 3-benzoate } 0.1\end{array}$ & $10.67 \pm 0.6667$ & $10.67 \pm 0.6667$ & $0 \pm 0.0$ & 0 & 0 \\
II & $\begin{array}{l}0 \pm 0.0^{* * *} \\
\mathrm{mg} / \mathrm{Kg}\end{array}$ & $0 \pm 0.0^{* * *}$ & $0 \pm 0.0^{* * *}$ & 100 & 100 \\
III & AEBCP $100 \mathrm{mg} / \mathrm{Kg}$ & $5.667 \pm 0.5578^{* * *}$ & $3.833 \pm 0.5426^{* * *}$ & $1.833 \pm 0.7491^{* * *}$ & 36.16 & 26.1 \\
IV & AEBCP $200 \mathrm{mg} / \mathrm{Kg}$ & $4.5 \pm 1.522^{* * *}$ & $2.333 \pm 0.9189^{* * *}$ & $2.167 \pm 0.3073^{* * *}$ & 37.5 & 40 \\
V & AEBCP $400 \mathrm{mg} / \mathrm{Kg}$ & $0.6667 \pm 0.4216^{* * *}$ & $0 \pm 0.0^{* * *}$ & $0.6667 \pm 0.3333^{* * *}$ & 43.16 & 90.32 \\
VI & AQEBCP $100 \mathrm{mg} / \mathrm{Kg}$ & $8.333 \pm 0.5578 \mathrm{~ns}$ & $7.667 \pm 0.4216^{*}$ & $0.6667 \pm 0.4216 \mathrm{~ns}$ & 19.5 & 13.76 \\
VII & AQEBCP $200 \mathrm{mg} / \mathrm{Kg}$ & $7.167 \pm 0.6009^{*}$ & $6.167 \pm 0.4773^{* *}$ & $1 \pm 0.4216^{*}$ & 25.08 & 20.35 \\
VIII & AQEBCP $400 \mathrm{mg} / \mathrm{Kg}$ & $5.833 \pm 0.7923^{* * *}$ & $4.167 \pm 0.4773^{* * *}$ & $1.667 \pm 0.2582^{* * *}$ & 37.58 & 22.16 \\
\hline
\end{tabular}

$\mathrm{n}=6$, Significant at ${ }^{*} \mathrm{p}<0.05,{ }^{* *} \mathrm{p}<0.01,{ }^{* * *} \mathrm{p}<0.001$ and $\mathrm{ns}=$ non-significant

AQEBCP-Aqueous extract of bark of $C$. pulcherrima, AEBCP-Alcoholic extract of bark of $C$. pulcherrima

TABLE 2: ANTI-OVULATORY EFFECT OF B-ESTRADIOL 3-BENZOATE, AEBCP AND AQEBCP ON UTERINE AND OVARY WEIGHTS IN RAT MODEL

\begin{tabular}{|c|c|c|c|}
\hline Groups & Treatment & Uterine Weight $(\mathrm{mg} / 100 \mathrm{~g})$ & Ovary Weight $(\mathrm{mg} / 100 \mathrm{~g})$ \\
\hline I & $\begin{array}{c}\text { Vehicle } \\
\text { (distilled water) }\end{array}$ & $87.40 \pm 3.397$ & $56.92 \pm 0.6964$ \\
\hline II & $\begin{array}{c}\text { B-Estradiol 3-benzoate } \\
0.1 \mathrm{mg} / \mathrm{Kg}\end{array}$ & $185.6 \pm 5.484^{* * *+}$ & $43.16 \pm 0.7647^{+* * *}$ \\
\hline III & AEBCP $100 \mathrm{mg} / \mathrm{Kg}$ & $145.1 \pm 5.063^{* * *}$ & $51.70 \pm 0.8267^{*+* t}$ \\
\hline IV & AEBCP $200 \mathrm{mg} / \mathrm{Kg}$ & $161.3 \pm 7.446^{*+*}$ & $48.67 \pm 1.017^{\star * *}$ \\
\hline V & AEBCP $400 \mathrm{mg} / \mathrm{Kg}$ & $179.5 \pm 2.808^{* * *}$ & $45.31 \pm 0.5816^{* * * *}$ \\
\hline VI & AQEBCP $100 \mathrm{mg} / \mathrm{Kg}$ & $92.74 \pm 1.591^{\mathrm{ns}}$ & $56.26 \pm 0.7319^{\text {ns }}$ \\
\hline VII & AQEBCP $200 \mathrm{mg} / \mathrm{Kg}$ & $113.7 \pm 3.377^{* * *}$ & $54.09 \pm 1.220^{*}$ \\
\hline VIII & AQEBCP $400 \mathrm{mg} / \mathrm{Kg}$ & $127.8 \pm 0.9818^{* * * *}$ & $52.87 \pm 1.048^{*}$ \\
\hline
\end{tabular}

$\mathrm{n}=6$, Significant at ${ }^{*} \mathrm{p}<0.05,{ }^{* *} \mathrm{p}<0.01,{ }^{* * *} \mathrm{p}<0.001$ and $\mathrm{ns}=$ non-significant

AQEBCP-Aqueous extract of bark of $C$. pulcherrima, AEBCP- Alcoholic extract of bark of $C$. pulcherrima 


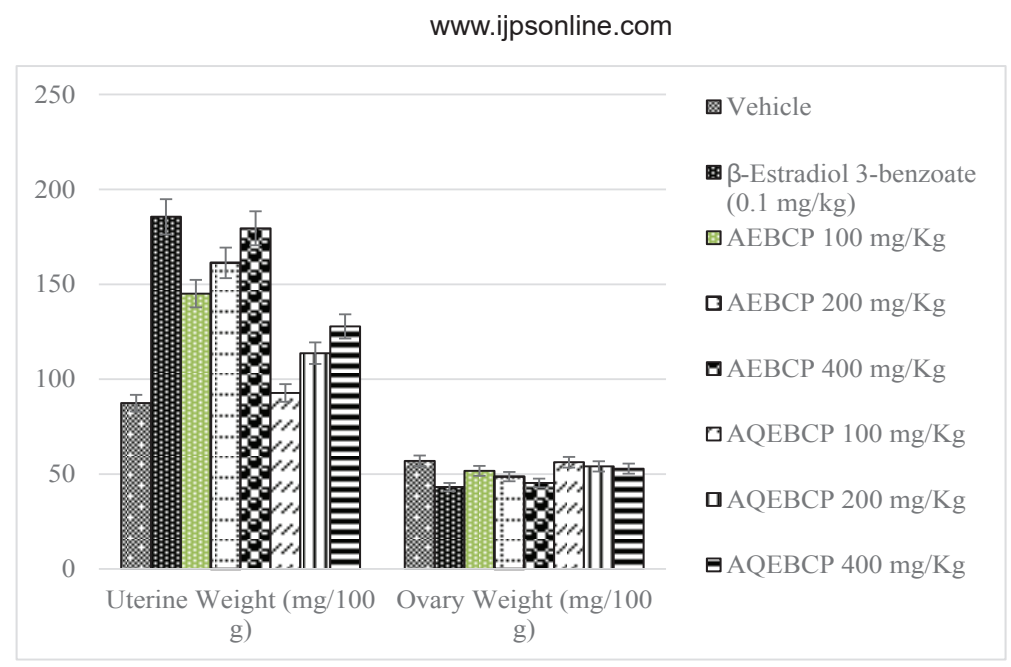

Fig. 2: Anti-ovulatory effect of $\beta$-Estradiol 3-benzoate, AEBCP and AQEBCP on uterine weight and ovary weight in rat model

is dependent on various factors. Population problem plays a major force and has a negative impact over it as the country needs to face drastic effects on particularly with employment, education, shelter, health care and sanitation \& environment ${ }^{[9]}$. Abnormal increase in population increases the scarcity of food, water, energy and supply of raw materials ${ }^{[10]}$. One of the best ways to avoid population related problems is birth control ${ }^{[11]}$. Population explosion affect economic \& health impact in the developing countries. Hence a global search for antifertility agents is continued throughout the World to tackle the problem ${ }^{[10]}$. Majority of research workers opine that traditional system of medicine will definitely provide a reliable contraceptive agent from the plant origin; World Health Organization (WHO) also encouraged the research workers to come out with a most valuable antifertility agent from the plants. Many years of scientific publications also proved antiproductive activity in a good number of plant extracts and their phytoconstituents with varied chemical structures/nature $^{[12]}$. Contraceptive agents either from natural origin (plant based products) or synthetic (chemical) substances are intended to inhibit either production of sperm or its motility in males and in the opposite sex not allowing formation of ovum and produce definite changes in endometrium render it non receptive to fertilized ovum. Among three popular methods to control population i.e. abortion, sterilization and contraception, the last one is the most popularizing one ${ }^{[10]}$. Sterilization methods based on traditional system using herbal medicines are used to prevent contraception. Drugs from the synthetic origin used for contraception with both oral and parenteral route of administration leave the individuals with a great number of adverse effects including increased trend of blood transaminases, cholesterol with other unwanted effects like headache, fatigue, depression, indigestion, weight gain, hypermenorrhea and intermenorrheal bleeding. Further these medications disturb protein, lipid and carbohydrates, enzymes and vitamins metabolism. Because of these risk factors associated with drugs necessitate exploring contraceptive drugs from indigenous medicinal plant origin ${ }^{[13]}$. Among the plants recorded in Indian medicinal literature, rural populations many use by these for one or other medicinal purposes. Further contraceptive effect with these plants is already recorded in ancient texts. These antifertility agents which are obtained from indigenous plants provide with larger benefits as the cost of these would be within the range of common man, especially in developing countries. Earlier it was reported that plants with estrogenic activity produce antifertility activity directly by influencing pituitary gland through peripheral modulation of leutinizing hormone (LH) and follicle stimulating hormone (FSH) by decreasing their secretion and also block ovulation. In addition, the plants may have abortifacient or antiprogestational effects $^{[14]}$. It was reported that estrogenic activity causes a significant increase in uterine weight, diameter of the uterus, thickness of endometrium, height of the endometrial epithelium and vaginal epithelial cornification in immature rats ${ }^{[14]}$. Antifertility activity effect may be due to uterine failure to form deciduoma in the endometrium, which is very essential for blastocyst implantation ${ }^{[15]}$. For implantation of zygote exact equilibrium of estrogen and progesterone is essential and any disturbance in the level of these hormones may cause antifertility effect. It was reported that decrease in wet weight of ovary after treatment with standard/both the extracts indicate an inhibition of ovulation through suppression of follicle stimulating hormone. Several factors like hormonal influence, alterations at implantation site, changes in endometrium 
of the uterus can be accounted for antifertility activity. Further it was suggested that loss of implantation may be due antizygotic, blasto cytotoxic or anti-implantation activities. It was earlier reported that an increase in the number of dead fetus as well as reduced survival ratio is an indication of the abortifacient activity The implantation index, resorption index and pre implantation loss are used to evaluate the number of blastocytes implanted in the uterus and also the underdeveloped ones. Further increase in resorption index indicates failure in the development of embryo after implantation ${ }^{[13]}$. It was reported that substances with antifertility activity produce these effects by inhibiting ovulation and steroidogenesis at ovarian level ${ }^{[15]}$. The antifertility activity of contraceptive steroids could be due to their estrogenic nature. These cause rapid passage of ova through oviducts and expulsion of the same from uterus and also due to degeneration of fertilized ova while transported uterus too early. This correlates with reduction in number of implants. Further uterine environment rather than the above mentioned plays an important role and a prolonged maintenance of diestrus phase due to the treatment also responsible for antifertility activity in this there is no change. Several phytochemicals like steroids, triterpinoids, flavonoids, myricitoside and caesalpin type diterpenoids along with sitosterol, alkaloids, terpenoids, phenolics, saponins and glycosides are already reported with their antifertility activity. Some of the phytoconstituents mentioned above are present (AEBCP: alkaloids, flavonoids, steroids, triterpenes, tannins, glycosides, saponins, carbohydrates, proteins and amino acids) (AQEBCP: alkaloids, flavonoids, steroids, triterpenes, tannins, glycosides, saponins, carbohydrates, proteins and amino acids) in both alcohol and aqueous extracts. Hence these can be accounted for the observed antifertility activity in the present study.

\section{Conflict of interests:}

The authors declared no conflicts of interest.

\section{REFERENCES}

1. Wang Z, Liu SH, Bo LJ, Zheng YZ, Shi J, Xu Y, et al. Clinical Features and Laboratory Data Analysis of Glucose-6Phosphate Dehydrogenase Deficiency. J Exp Hematol 2018;26(5):1437-41.

2. Carlsson AC, Bandstein N, Roos A, Hammarsten O, Holzmann
MJ. High-sensitivity cardiac troponin T levels in the emergency department in patients with chest pain but no myocardial infarction. Int J Cardiol 2017;228:253-9.

3. Belle L, Cayla G, Cottin Y, Coste P, Khalife K, Labèque J-N, et al. French Registry on Acute ST-elevation and nonST-elevation Myocardial Infarction 2015 (FAST-MI 2015). Design and baseline data. Arch Cardiovasc Dis 2017;110(6):366-78.

4. Zhongkai H, Yuhan Z, Feng Y. Effects of resveratrol on myocardial protection and Akt/JNK3/caspase-3 signaling pathway in rats with acute myocardial infarction. Chin J Evid Based Cardiovasc Med 2018;10:1310-4.

5. Xiaoxiao J, Zuhua Z, Dong C. Effect of resveratrol on cardiac nerve remodeling in rats with acute myocardial infarction and its mechanism. J Chin Med University 2018;47:27-30.

6. Chengjun L, Mei D, Ren Faxin. The effect of resveratrol on the levels of myocardial injury markers in AMI rats through the c-fos pathway. Chin J Evid Based Cardiovasc Med 2020;12:436-42.

7. Dan L, Fei H, Ke P. The protective effect and mechanism of resveratrol post-treatment on myocardial ischemia/reperfusion injury in rats. Chin Emerg Med 2018;38:910-4.

8. Zhongkai H, Yuhan Z, Yao Feng. Resveratrol improves the inflammatory response after acute myocardial infarction in rats by silencing the information regulator 1/nuclear factor kappa B pathway. Chin J Cardiol 2019;24:62-5.

9. Tang F, Guo S, Liao H, Yu P, Wang L, Song X, et al. Resveratrol Enhances Neurite Outgrowth and Synaptogenesis Via Sonic Hedgehog Signaling Following Oxygen-Glucose Deprivation/ Reoxygenation Injury. Cell Physiol Biochem 2017;43(2):85269.

10. Waterford SD, Eusanio MD, Ehrlich MP, Reece TB, Desai ND, Sundt TM, et al. Postoperative myocardial infarction in acute type A aortic dissection: A report from the International Registry of Acute Aortic Dissection. J Thorac Cardiovasc Surg 2017;153(3):521-7.

11. Bahit MC, Kochar A, Granger CB. Post-Myocardial infarction heart failure. JACC Heart Fail 2018;6:179-86.

12. Xiang C, Wang Y, Zhang H, Han F. The role of endoplasmic reticulum stress in neurodegenerative disease. Apoptosis 2017;22(1):1-26.

13. Bai X, Geng J, Li X, Wan J, Liu J, Zhou Z, et al. Long noncoding RNA LINC01619 regulates MicroRNA-27a/ Forkhead Box Protein O1 and endoplasmic reticulum stressmediated podocyte injury in diabetic nephropathy. Antioxid Redox Signal 2018;29(4):355-76.

14. Lumley EC, Osborn AR, Scott JE, Scholl AG, Mercado V, McMahan YT, et al. Moderate endoplasmic reticulum stress activates a PERK and p38-dependent apoptosis. Cell Stress Chaperones 2017;22(1):1-12.

15. Fan P, Tyagi AK, Agboke FA, Pokharel N, Jordan VC. Abstract 2332: Integral modulation of nuclear factor-kappa B activation by $\mathrm{C} / \mathrm{EBP} \beta$ and the endoplasmic reticulum stress sensor PERK to mediate estrogen-induced apoptosis in estrogen-deprived breast cancer cells. Cancer Res 2017;77(13):2332. 